\title{
Article
}

\section{Transcriptomic Characterization of Nitrate-Enhanced Stevioside Glycoside Synthesis in Stevia (Stevia rebaudiana) Bertoni}

\author{
Yuming Sun ${ }^{1,2}$, Ting Zhang ${ }^{1,2}$, Xiaoyang Xu ${ }^{1,2}$, Yongheng Yang ${ }^{1,2}$, Haiying Tong ${ }^{1,2}$, Luis Alejandro Jose Mur ${ }^{3}$ \\ and Haiyan Yuan ${ }^{1,2, *}$ \\ 1 Jiangsu Key Laboratory for the Research and Utilization of Plant Resources, Institute of Botany, \\ Jiangsu Province and Chinese Academy of Sciences, No. 1 Qianhuhoucun Village, Zhongshan Gate, \\ Nanjing 210014, China; yumingsun@cnbg.net (Y.S.); zhangting901014@cnbg.net (T.Z.); \\ xuxiaoyang@cnbg.net (X.X.); yongheng@cnbg.net (Y.Y.); haiyingtong@cnbg.net (H.T.) \\ 2 The Jiangsu Provincial Platform for Conservation and Utilization of Agricultural Germplasm, \\ Nanjing 210014, China \\ 3 Institute of Biological, Environmental and Rural Sciences, Aberystwyth University, \\ Aberystwyth SY23 3DA, UK; lum@aber.ac.uk \\ * Correspondence: yuanhaiyan@cnbg.net
}

check for

updates

Citation: Sun, Y.; Zhang, T.; Xu, X.; Yang, Y.; Tong, H.; Mur, L.A.J.; Yuan, H. Transcriptomic Characterization of Nitrate-Enhanced Stevioside Glycoside Synthesis in Stevia (Stevia rebaudiana) Bertoni. Int. J. Mol. Sci. 2021, 22, 8549. https://doi.org/ $10.3390 /$ ijms 22168549

Academic Editors: Vladimir Totev Valkov and Maurizio Chiurazzi

Received: 13 July 2021

Accepted: 6 August 2021

Published: 9 August 2021

Publisher's Note: MDPI stays neutral with regard to jurisdictional claims in published maps and institutional affiliations.

Copyright: (c) 2021 by the authors. Licensee MDPI, Basel, Switzerland. This article is an open access article distributed under the terms and conditions of the Creative Commons Attribution (CC BY) license (https:// creativecommons.org/licenses/by/ $4.0 /)$.

\begin{abstract}
Nitrogen forms (nitrate $\left(\mathrm{NO}_{3}{ }^{-}\right)$or ammonium $\left(\mathrm{NH}_{4}{ }^{+}\right)$) are vital to plant growth and metabolism. In stevia (Stevia rebaudiana), it is important to assess whether nitrogen forms can influence the synthesis of the high-value terpene metabolites-steviol glycosides (SGs), together with the underlying mechanisms. Field and pot experiments were performed where stevia plants were fertilized with either $\mathrm{NO}_{3}{ }^{-}$or $\mathrm{NH}_{4}{ }^{+}$nutrition to the same level of nitrogen. Physiological measurements suggested that nitrogen forms had no significant impact on biomass and the total nitrogen content of stevia leaves, but $\mathrm{NO}_{3}{ }^{-}$-enhanced leaf SGs contents. Transcriptomic analysis identified 397 genes that were differentially expressed (DEGs) between $\mathrm{NO}_{3}{ }^{-}$and $\mathrm{NH}_{4}{ }^{+}$treatments Assessment of the DEGs highlighted the responses in secondary metabolism, particularly in terpenoid metabolism, to nitrogen forms. Further examinations of the expression patterns of SGs synthesisrelated genes and potential transcription factors suggested that GGPPS and CPS genes, as well as the WRKY and MYB transcription factors, could be driving $\mathrm{N}$ form-regulated SG synthesis. We concluded that $\mathrm{NO}_{3}{ }^{-}$, rather than $\mathrm{NH}_{4}{ }^{+}$, can promote leaf SG synthesis via the $\mathrm{NO}_{3}{ }^{-}-\mathrm{MYB} / \mathrm{WRKY}$ GGPPS/CPS module. Our study suggests that insights into the molecular mechanism of how SG synthesis can be affected by nitrogen forms.
\end{abstract}

Keywords: Stevia rebaudiana; nitrogen forms; transcriptome; secondary metabolism; transcription factors

\section{Introduction}

As the global standard of living improves, people are aiming to pursue a healthier lifestyle. The excessive intake of sugars has increased the risk of dental caries, diabetes, obesity and hyperlipidemia, so that the alternative new sugar crop, stevia (Stevia rebaudiana Bertoni), has received increasing attention and acceptance [1,2]. Stevia plants are rich in steviol glycosides (SGs), a class of tetracyclic diterpenoid compounds, especially in leaf tissue [3]. Stevioside (STV) and rebaudiosides A (Reb A) are the most abundant SGs and can account for about 4-20\% of the dry leaf weight. Other less abundant SGs, such as Reb C, Reb F and Dulcoside A, may be important in providing taste to SG mixtures [4]. SGs can be used as food additives and are sweeter than cane sugar and beet sugar, but have a lesser calorific value. These properties have greatly increased worldwide demand for SGs and resulted in increased commercial cultivation of stevia plants [5,6]. Given this, improving the SG levels in stevia plants through agricultural practices is of vital importance for the development of the stevia industry.

SG metabolism in stevia plants may be influenced by multiple agricultural factors such as planting density, water management, arbuscular mycorrhiza infections and nutri- 
tion [7-9]. Amongst these, nitrogen $(\mathrm{N})$ nutrition is one of the most important factors that influence stevia productivity, as $\mathrm{N}$ is deeply implicated in plant development as well as metabolic processes $[10,11]$. Previous studies, including ours, have shown that $\mathrm{N}$ fertilization can enhance leaf photosynthesis rate and aboveground biomass, but, if improperly used, may inhibit SG synthesis and accumulation [12-15]. Thus, we found that SG levels can be increased to a certain extent through optimizing $\mathrm{N}$ topdressing strategies [16]. However, there was a negative correlation between SG synthesis and leaf N content, as well as the leaf biomass under different $\mathrm{N}$ fertilization rates and topdressing strategies. Recently published transcriptome work attributed the N-inhibited SG metabolism to either shift in the balance of commitment to plant growth versus differentiation or transcriptionally repressive events after adding $\mathrm{N}$ [17]. This work highlights the need for a subtle implementation of $\mathrm{N}$ fertilization rates or timing to promote biomass but limit negative effects on the levels of SGs.

The major forms of mineral $\mathrm{N}$, ammonium $\left(\mathrm{NH}_{4}{ }^{+}\right)$and nitrate $\left(\mathrm{NO}_{3}{ }^{-}\right)$are differently absorbed, assimilated, and they also have differential impacts on plant metabolism. The assimilatory costs of $\mathrm{NH}_{4}{ }^{+}$are lower than $\mathrm{NO}_{3}{ }^{-}$because it can be directly assimilated in root tissue, whilst $\mathrm{NO}_{3}{ }^{-}$needs to be transported to the leaves for further reduction to $\mathrm{NH}_{4}{ }^{+}[18,19]$. The differential effects of $\mathrm{NO}_{3}{ }^{-}$have been linked to leaf photorespiration and the tricarboxylic acid cycle to affect other central metabolic pathways [20,21]. Further, an association between $\mathrm{NH}_{4}{ }^{+}$assimilation and phosphoenolpyruvate carboxylase activity involves altered carbon $(\mathrm{C})$ and energetics metabolism [22,23]. Crucially, the form of $\mathrm{N}$ affects the terpenoid metabolism of plant. A higher $\mathrm{NO}_{3}{ }^{-} / \mathrm{NH}_{4}{ }^{+}$ratio has been shown to significantly promote terpenoid synthesis in terpenoid-rich plants such as Brassica species [24] and Prunella vulgaris [25]. However, opposite results have also been documented in Andrographis paniculata [26], Capsicum annuum [27] and Occimum basilicum [28]. Thus, $\mathrm{N}$ forms can reshape plant terpenoid metabolism, but the exact action may differ between plant species. It is therefore important to investigate the relationship between $\mathrm{N}$ forms and SGs metabolism in stevia leaves, as well as define the underlying mechanisms.

In the current study, we combined pot and field experiments to demonstrate that $\mathrm{NO}_{3}{ }^{-}$rather than $\mathrm{NH}_{4}{ }^{+}$fertilization can significantly increase leaf SG contents without influencing leaf biomass formation. Via further transcriptomic analysis, we found that such effects are likely due to the upregulation of the terpenoid synthesis pathway by $\mathrm{NO}_{3}{ }^{-}$ treatment. This $\mathrm{NO}_{3}{ }^{-}$-induced change could be attributed to the transcription factors belonging to MYB and/or WRKY families. Our results have implications for how SGs synthesis can be maximized in the field-grown stevia.

\section{Results}

2.1. Effects of Nitrogen Forms on the Biomass, Carbon-Nitrogen Status and SGs Content in the Leaves of Stevia Plants Grown under Pot and Field Conditions

Different forms of $\mathrm{N}$ fertilization $\left(\left(\mathrm{NH}_{4}{ }^{+}\right)\right.$vs. $\left.\left(\mathrm{NO}_{3}{ }^{-}\right)\right)$did not significantly affect the biomass of stevia leaves. This was reflected in the similarities in TN, TC and $\mathrm{C} / \mathrm{N}$ ratio between $\mathrm{NH}_{4}{ }^{+}$- and $\mathrm{NO}_{3}{ }^{-}$-fed stevia plants (Table 1). However, whilst leaf $\mathrm{NH}_{4}{ }^{+}$content was not significantly changed by $\mathrm{N}$ forms, $\mathrm{NO}_{3}{ }^{-}$content was significantly increased in $\mathrm{NO}_{3}{ }^{-}$treatments, under both pot and field conditions.

$\mathrm{N}$ application forms significantly altered the contents of leaf SGs. The major SG in stevia plants, Reb-A, was considerably increased by $\mathrm{NO}_{3}{ }^{-}$by $50.79 \%$ and $15.14 \%$ under pot and field conditions, respectively, compared to $\mathrm{NH}_{4}{ }^{+}$treatment (Figure 1A). The leaf contents of STV and Reb-C were also increased by $\mathrm{NO}_{3}{ }^{-}$rather than $\mathrm{NH}_{4}{ }^{+}$treatment (Figure 1B,C). However, total SGs (TSGs) contents were significantly greater in $\mathrm{NO}_{3}{ }^{-}$-fed compared to $\mathrm{NH}_{4}{ }^{+}$-fed plants (Figure 1D). When examining the effects of the "experimental cultures" used, a higher leaf STV content but lower Reb-A and Reb-C contents were observed in stevia plants grown in pot than field culture. No significant interaction effect was exhibited in the content of either a single SG or TSGs. 
Table 1. Effect of different nitrogen forms on the biomass $\left(\mathrm{g}\right.$ plant $\left.{ }^{-1}\right)$, total nitrogen ( $\left.\mathrm{TN}, \mathrm{mg} \mathrm{g}^{-1} \mathrm{DW}\right)$ content, total carbon (TC, $\left.\mathrm{mg} \mathrm{g}^{-1} \mathrm{DW}\right)$ content, carbon-nitrogen ratio $(\mathrm{C} / \mathrm{N})$, ammonium nitrogen $\left(\mathrm{A}-\mathrm{N}, \mathrm{mg} \mathrm{g}^{-1} \mathrm{FW}\right)$ content and nitrate nitrogen $\left(\mathrm{N}-\mathrm{N}, \mathrm{mg} \mathrm{g}^{-1} \mathrm{FW}\right)$ content in stevia leaves.

\begin{tabular}{|c|c|c|c|c|c|c|c|}
\hline $\begin{array}{c}\text { Experimental } \\
\text { Condition }\end{array}$ & Treatment & Leaf Biomass & TN & TC & $\mathrm{C} / \mathrm{N}$ & A-N & $\mathrm{N}-\mathrm{N}$ \\
\hline \multirow[b]{2}{*}{ Pot } & $\mathrm{A}-\mathrm{N}$ & $2.90 \pm 0.18 b$ & $32.43 \pm 3.61 \mathrm{~b}$ & $461.37 \pm 13.84 \mathrm{bc}$ & $14.36 \pm 1.79 \mathrm{~b}$ & $0.13 \pm 0.00 \mathrm{a}$ & $0.32 \pm 0.02 \mathrm{c}$ \\
\hline & $\mathrm{N}-\mathrm{N}$ & $2.65 \pm 0.12 b$ & $30.14 \pm 0.88 b$ & $450.38 \pm 15.08 c$ & $14.96 \pm 0.94 \mathrm{~b}$ & $0.12 \pm 0.02 \mathrm{a}$ & $0.44 \pm 0.05 \mathrm{ab}$ \\
\hline \multirow{2}{*}{ Field } & $\mathrm{A}-\mathrm{N}$ & $5.74 \pm 0.97 \mathrm{a}$ & $25.11 \pm 0.75 \mathrm{a}$ & $491.04 \pm 13.38 \mathrm{a}$ & $19.57 \pm 0.71 \mathrm{a}$ & $0.12 \pm 0.00 \mathrm{a}$ & $0.34 \pm 0.03 \mathrm{bc}$ \\
\hline & $\mathrm{N}-\mathrm{N}$ & $4.99 \pm 1.18 \mathrm{a}$ & $24.44 \pm 0.44 \mathrm{a}$ & $482.86 \pm 4.69 \mathrm{ab}$ & $19.76 \pm 0.30 \mathrm{a}$ & $0.12 \pm 0.01 \mathrm{a}$ & $0.49 \pm 0.09 a$ \\
\hline \multicolumn{2}{|c|}{$\mathrm{N}$ forms } & ns & ns & ns & ns & ns & $* *$ \\
\hline \multicolumn{2}{|c|}{ Experimental cultures } & $* *$ & $* *$ & ** & $* *$ & $* *$ & ns \\
\hline \multicolumn{2}{|c|}{$\begin{array}{l}\mathrm{N} \text { forms * Experimental } \\
\text { cultures }\end{array}$} & ns & ns & ns & ns & ns & ns \\
\hline
\end{tabular}

Stevia plants growth under pot or field condition were supplied with ammonium-nitrogen (A-N) or nitrate-nitrogen (N-N) at the same $\mathrm{N}$ levels. Values represent the means \pm SD of three biological replicates. ANOVA results are indicated; different letters indicate significant differences in the same indicator, ${ }^{*}$ and ${ }^{* *}$ indicate significant difference at 0.05 and 0.01 probability levels, respectively; ns means nonsignificant difference. DW: dry weight, FW: fresh weight.
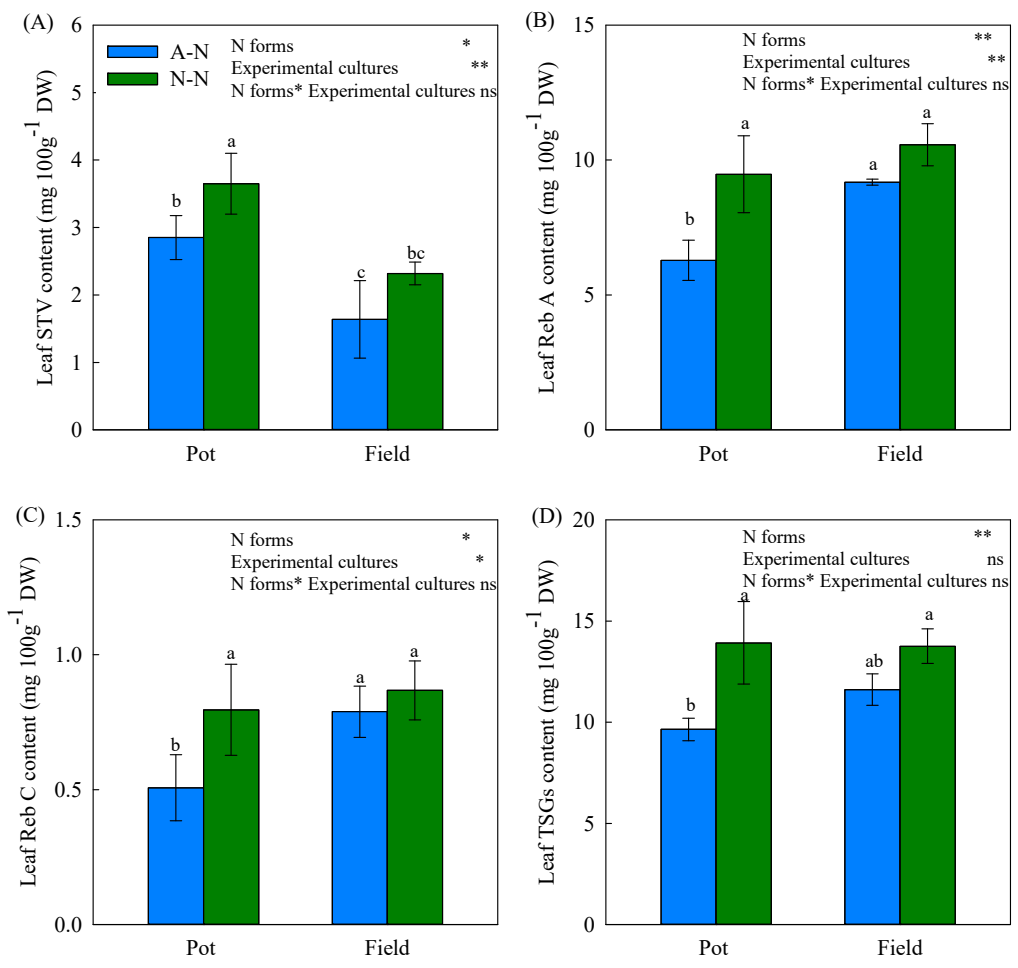

Figure 1. Effect of nitrogen forms on the leaf contents of stevioside (STV, A), rebaudioside A (Reb A, B), rebaudioside C (Reb C, C) and total steviol glycosides (TSGs, D) of stevia plant growing in pot and field conditions ("experimental cultures"). Stevia plants growth under pot or field conditions were fed with ammonium-nitrogen (A-N) or nitrate-nitrogen (N-N) to the same $\mathrm{N}$ level. Values represent the means $\pm \mathrm{SD}$ of three biological replicates. ANOVA results are indicated; different letters indicate significant differences in the same indicator, ${ }^{*}, *$ and $n$ indicate significant difference at $0.05,0.01$ probability levels and nonsignificant difference, respectively.

\subsection{Global Analysis of RNA-Seq Data}

Stevia leaves treated by different $\mathrm{N}$ forms were sampled and sequenced for transcriptome analysis. Approximately 21,444,479 and 25,727,058 clean reads were obtained from $\mathrm{NH}_{4}{ }^{+}$-and $\mathrm{NO}_{3}{ }^{-}$-treated samples, which corresponded to $6.41 \mathrm{~GB}$ and $7.70 \mathrm{~GB}$ of data (Supplemental Table S1), respectively. In addition, the frequency of $>30$ Phred quality score (Q30) was higher than $94.27 \%$ and the guanine-cytosine (GC) content was higher than $45.42 \%$ for all the samples, indicating that the sequence data were of high quality. Then, $60.45-76.30 \%$ of the clean reads were mapped to the reference genome of stevia 
plants (https:/ / doi.org/10.6084/m9.figshare.14169491.v1 (accessed on 5 March 2021)) [29], and $48.83-62.55 \%$ of the clean reads were uniquely mapped onto the stevia genome. In total, 35,424 and 36,063 genes were expressed (FPKM > 0) in the A-N and N-N treatments, respectively (Supplemental Table S1).

\subsection{Identification of DEGs Responsive to $N$ Forms}

To identify the DEGs' specific response to $\mathrm{N}$ forms, the calculations were based on FPKM outputs where a fold change $\geq 2$ and false discovery rate (FDR) $<0.01$ were used as thresholds to be passed. A total of 397 DEGs were identified, with 236 upregulated genes and 161 downregulated genes (Figure 2A). To explore the functions of these genes, the DEG sets were assigned to 36 functional groups by gene ontology (GO) annotation analysis, including "biological process" (BP, 14 subcategories), "cellular component" (CC, 11 subcategories) and "molecular function" (MF, 11 subcategories) (Supplemental Figure S1). In the BP group, the majority of GO terms were linked to metabolic process, cellular process and single-organism process. For the CC group, the top five subcategories were membrane, cell, cell part, membrane part and organelle. Catalytic activity and binding were the dominant subcategories in the MF group.

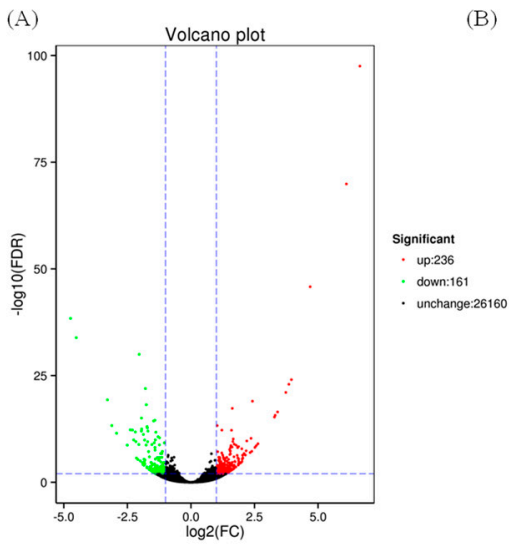

(B)

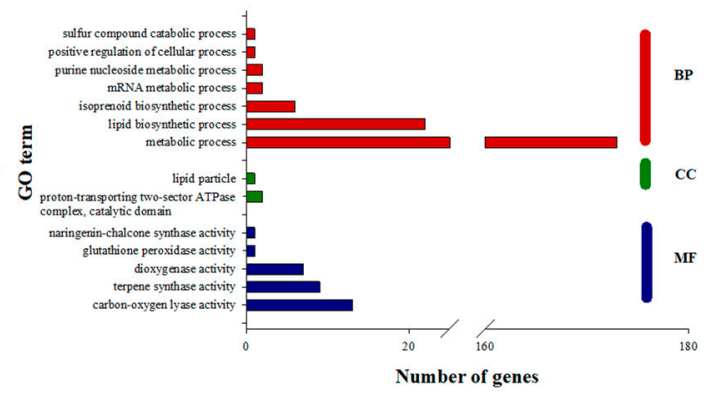

Figure 2. Volcano plot (A) and gene ontology (GO, B) analysis of differentially expressed genes (DEGs) between ammonium (A-N)- and nitrate (N-N)- treated stevia leaves. In (A), the red dots represent the upregulated DEGs, while the green dots represent the downregulated DEGs, with a minimum fold-change threshold of 2 and a significant level of 0.05 . In (B), the $y$-axis represents different GO terms that belong to BP (biological processes), CC (cell component) or MF (molecular functions) subcategories, while the value on the $x$-axis shows the number of genes in the corresponding GO term.

GO enrichment analysis was performed to characterize the main biological functions of DEGs. This indicated that metabolic process (GO: 0008152), lipid biosynthesis process (GO: 0008610) and isoprenoid biosynthetic process (GO: 0008299) were the most significant enrichment terms in the BP category, whilst the carbon-oxygen lyase activity (GO: 0016835) and terpene synthase activity (GO: 0010333) were enriched in the MF category (Figure 2B).

KEGG enrichment analysis was then conducted to assign the DEGs to cellular pathways. Interestingly, these DEGs were enriched in pathways including "diterpenoid biosynthesis", "phenylpropanoid biosynthesis", "fatty acid elongation" and "cutin, suberine and wax biosynthesis", following $\mathrm{NO}_{3}{ }^{-}$rather than $\mathrm{NH}_{4}{ }^{+}$treatment (Figure 3, Supplemental Figure S2A). When considering those DEGs downregulated by $\mathrm{NO}_{3}{ }^{-}$, the "carbon metabolism" together with "amino acid metabolism" was prominent (Supplemental Figure S2B). 


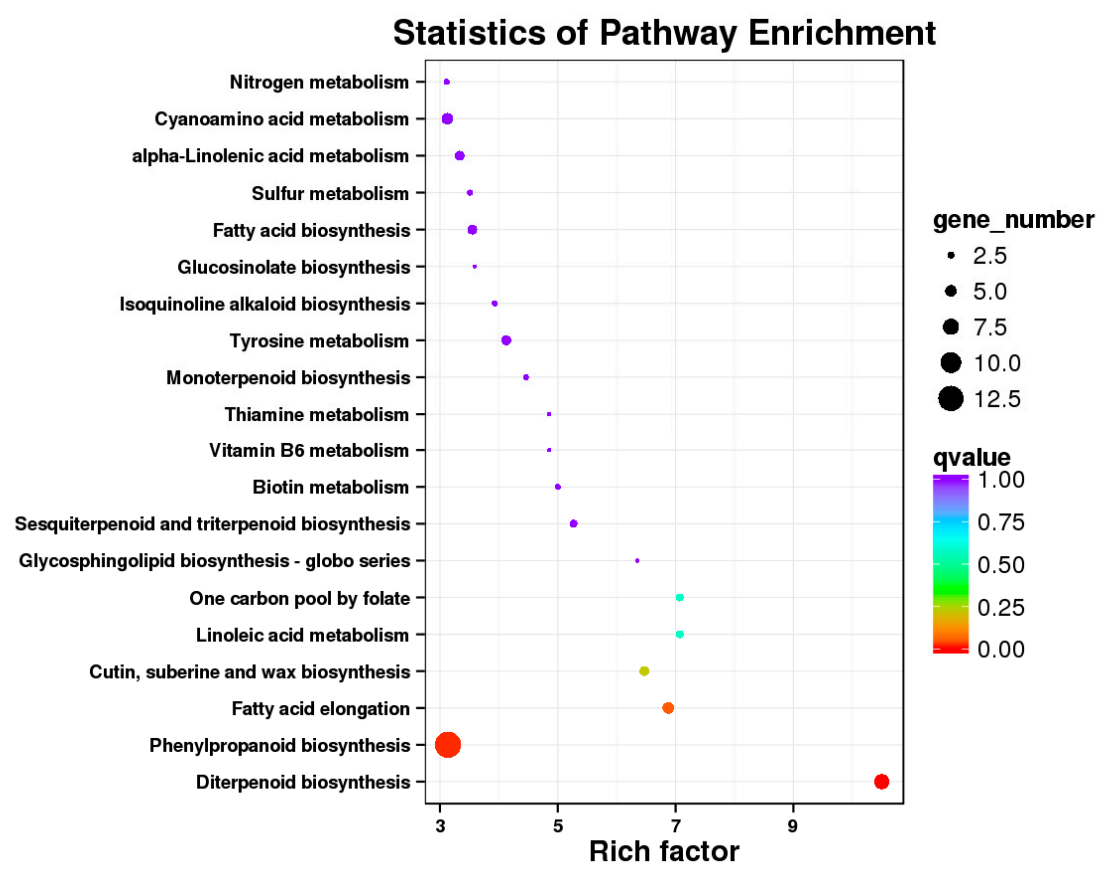

Figure 3. KEGG (Kyoto encyclopedia of genes and genomes, C) pathway enrichment analysis of differentially expressed genes (DEGs) between the two groups (ammonium (A-N) vs. nitrate (N-N)). The $x$-axis indicates the enrichment factor, while the color of each circle relates to the enriched Q-value and the size is equivalent to the gene numbers mapped to the pathway.

\subsection{MapMan Analysis}

To investigate the metabolic pathways implicated in the response to $\mathrm{N}$ forms from a global perspective, we analyzed 397 DEGs using MapMan analysis. Most of the DEGs were assigned to four different metabolic pathways, including "cell wall", "lipids", "secondary metabolism" and "amino acids" (Figure 4A). Then, we specifically analyzed the response of secondary metabolism, which is closely related to SGs' synthesis. Interestingly, genes involved in terpenoid synthesis and phenylpropanoids and lignin and lignans' metabolism were significantly enhanced by $\mathrm{NO}_{3}{ }^{-}$nutrition when compared with $\mathrm{NH}_{4}{ }^{+}$nutrition (Figure 4B). SGs biosynthesis mainly contains four modules after the glycolysis processes, which are methylerythritol 4-phosphate (MEP) module, terpene synthesis module, cytochrome P450 module and glycosylation module (Supplemental Figure S3) [5]. In our MapMan assessment, we observed significantly enhanced expressions of genes involved in the MEP pathway.

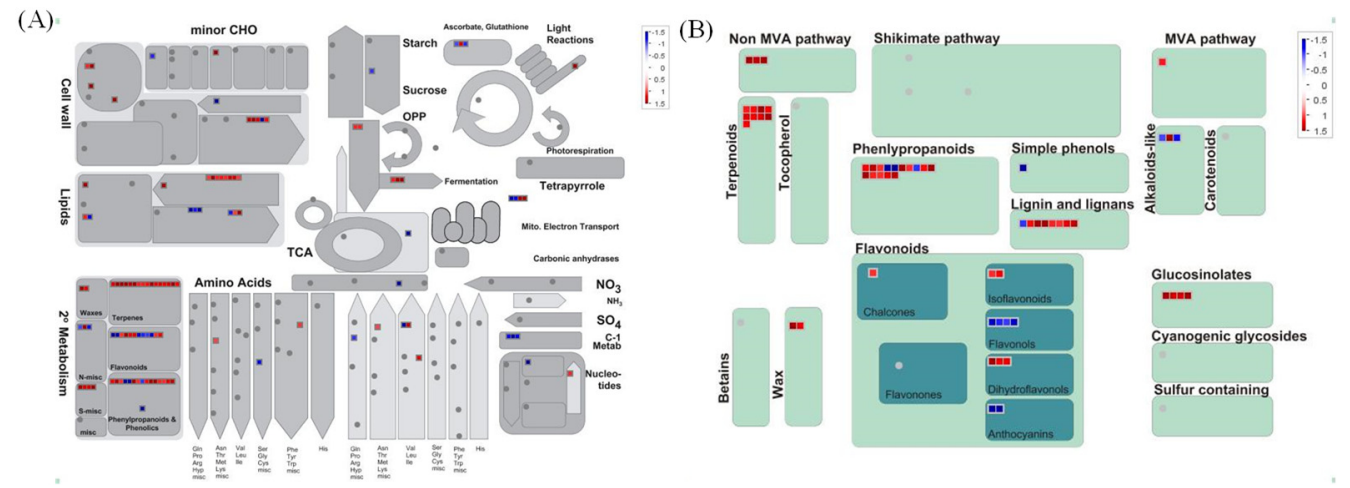

Figure 4. Mapping genes on overview map (A) and a secondary metabolism map (B) that were differentially expressed in nitrate (N-N)-treated in comparison to ammonium (A-N)-treated stevia leaves. 


\subsection{Effect of Nitrogen Forms on the Expression of Genes-Encoding SG Synthesis in Stevia Leaves}

We next focused on the expression of specific genes in the MEP module (Supplemental Figure S3). The expression of genes encoding 1-deoxy-D-xylulose-5-phosphate synthase (DXS) and 1-deoxy-D-xylulose 5-phosphate reductoisomerase (DXR) were higher under $\mathrm{NO}_{3}{ }^{-}$nutrition than $\mathrm{NH}_{4}{ }^{+}$nutrition (Figure 5). However, the expressions of other genes involved in the MEP module did not significantly differ between $\mathrm{NH}_{4}{ }^{+}$- and $\mathrm{NO}_{3}{ }^{-}$fed plants. Genes encoding geranylgeranyl pyrophosphate synthase (GGPPS) and entcopalylpyrophosphate synthase (CPS) in the terpene synthesis module, as well as the genes encoding UDP-glycosyltransferase 85C2 (UGT85C2) in the glycosylation module, were upregulated by $\mathrm{NO}_{3}{ }^{-}$treatments compared to $\mathrm{NH}_{4}{ }^{+}$. In contrast, those encoding ent-copalyl diphosphate synthase (KS), UDP-glycosyltransferase 74G1 (UGT74G1) and UDP-glycosyltransferase 76G1 (UGT76G1) were not changed by N forms (Figure 5). No significant difference was observed for the genes encoding cytochrome P450 enzymes, ent-kaurene oxidase $(\mathrm{KO})$ and kaurenoic acid hydroxylase (KAH) when comparing the two treatments.

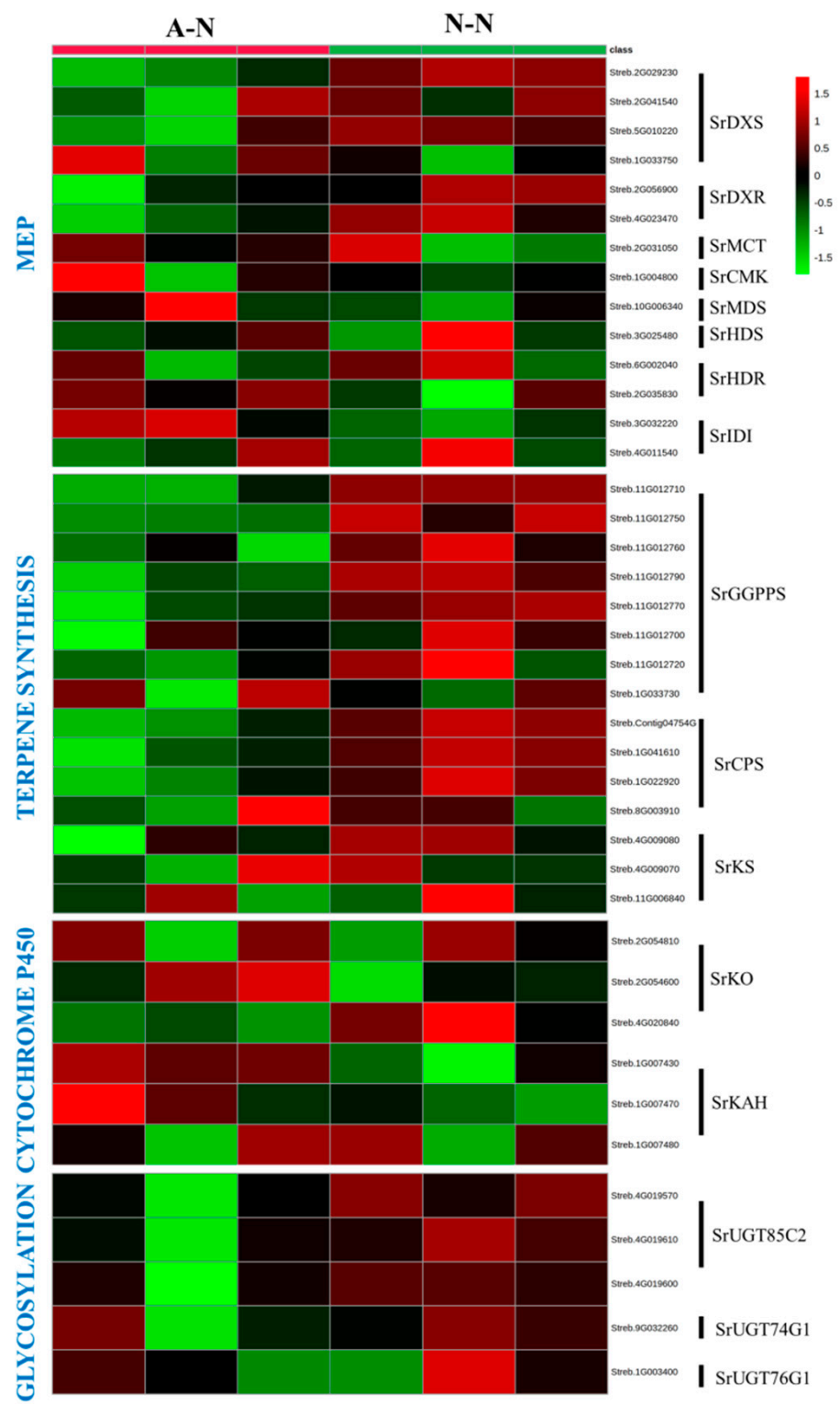

Figure 5. Heatmap showing the expression profiles of the genes involved in steviol glycosides synthesis in ammonium (A-N)- and nitrate (N-N)-treated stevia leaves. 


\subsection{Analysis of Transcription Factors (TFs) Responses to N Forms}

We next analyzed the expression of TFs to fully understand the mechanism of $\mathrm{NO}_{3}{ }^{-}$affected terpenoid biosynthesis. A total of 23 differentially expressed TFs were identified by comparative analysis between $\mathrm{NH}_{4}{ }^{+}$- and $\mathrm{NO}_{3}{ }^{-}$-fed plants. Among these TFs, WRKY (5), MYB (3), HSF (3) and AP2/ERF-ERF (3) were most prominent (Figure 6). $\mathrm{NO}_{3}{ }^{-}$treatment positively regulated the expression of genes relating to the WRKY, MYB and HSF families, while opposite results were observed for AP2/ERF-ERF family genes.

(A)

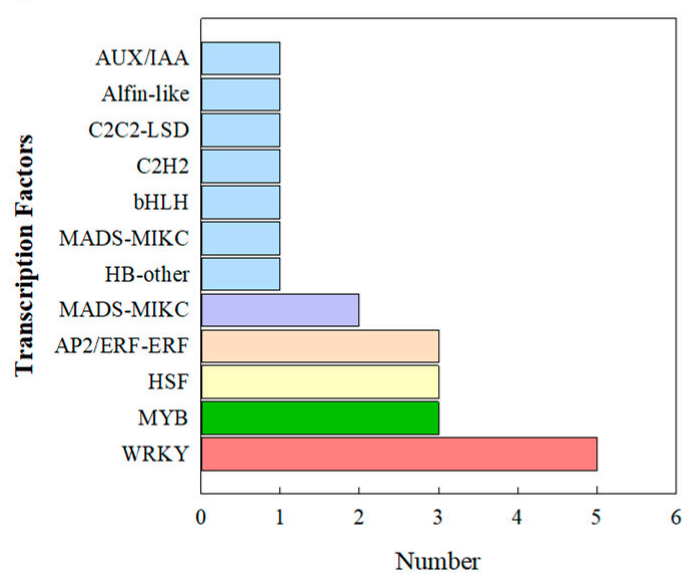

(B)

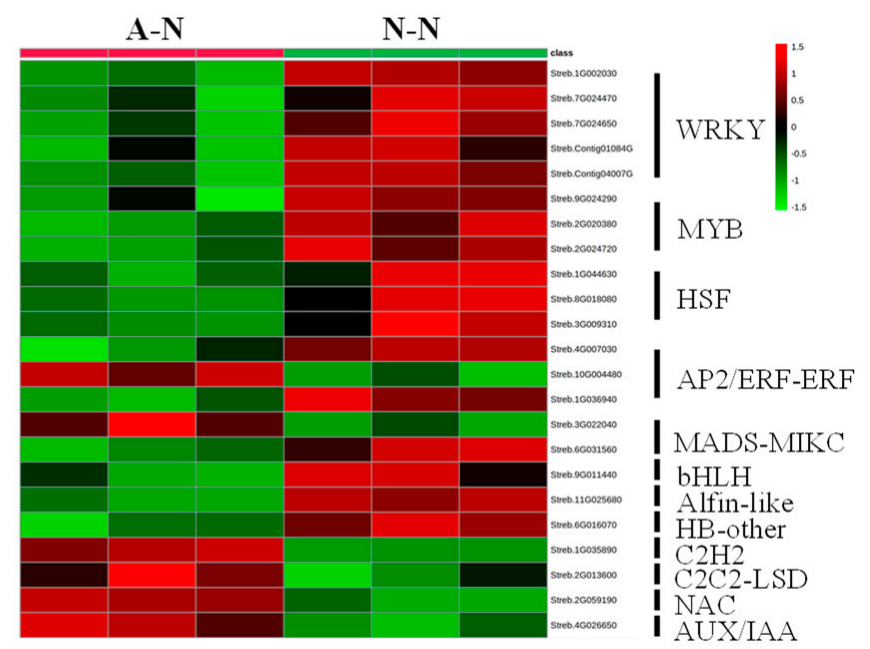

Figure 6. Transcription factors identified from the DEGs between ammonium (A-N)- and nitrate (N-N)-treated stevia (A) and a heatmap showing their expression profiles (B).

\subsection{Validation of Gene Expression Patterns}

To validate some key observations from the RNA-seq data, the expression of nine genes involving in the SG biosynthesis was analyzed by qRT-PCR. Both the RNA-Seq and qRT-PCR results showed that $\mathrm{NO}_{3}{ }^{-}$nutrition significantly increased the expression levels of SrDXR (Streb.2G056900), GGPPS (Streb.11G012710) and UGT85C2 (Streb.4G019570), while the expressions of SrMDS (Streb.10G006340) and SrKAH (Streb.1G007430) were reduced by $\mathrm{NO}_{3}{ }^{-}$treatment compared to $\mathrm{NH}_{4}{ }^{+}$(Figure 7). No significant difference was observed in other genes in either of the two methods. Taken together, the comparative analysis of the expression patterns of these genes from RNA-Seq and qRT-PCR results showed a good match, which suggested the reliability of the RNA-Seq results used in this study. 

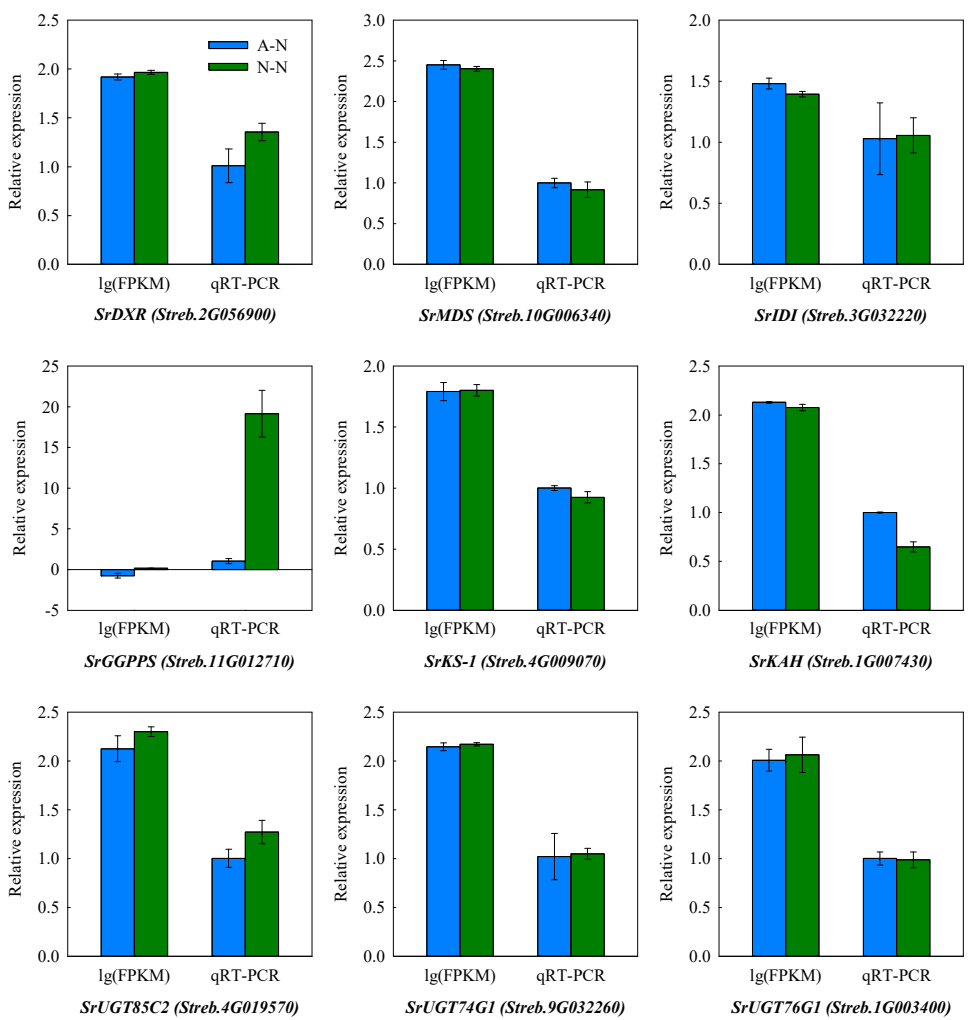

Figure 7. Quantitative real-time PCR (qRT-PCR) assessments of 9 genes encoding the key enzymes involving in steviol glycosides synthesis. Stevia plants were fed with either the ammonium form of nitrogen $(A-N)$ or the nitrate form of nitrogen $(\mathrm{N}-\mathrm{N})$. Values represent the mean $\pm \mathrm{SD}$ of three biological replicates.

\section{Discussion}

The absorption of $\mathrm{N}$ by plants is critical for plant growth but incorporates preferences for different forms of $\mathrm{N}$ to influence metabolic programming. Thus, supply of different $\mathrm{N}$ forms will alter plant $\mathrm{N}$ assimilation process, $\mathrm{C}$ fixation efficiency and subsequently the formation of biomass [30,31]. More specifically, the metabolism of specific plant compounds, including terpenoids, can be influenced by $\mathrm{N}$ forms. For instance, the production of andrographolide in Andrographis paniculata [26] and taxol in Taxus yunnanensis [32] could be enhanced by $\mathrm{NH}_{4}{ }^{+}$nutrition when compared to $\mathrm{NO}_{3}{ }^{-}$. In contrast, $\mathrm{NO}_{3}{ }^{-}$nutrition, rather than $\mathrm{NH}_{4}{ }^{+}$, increased the synthesis of periplocin in Periploca sepium [33], ginseng saponin in Panax quinquefolium [34] and essential oil in Anethum graveolens [35]. This was in line with our data, whereby $\mathrm{NO}_{3}{ }^{-}$was linked to a higher leaf SGs contents that could be linked to elevated expression of SGs synthesis genes (Figures 1 and 5). However, Qin, et al. [36] found that the relationship between $\mathrm{NH}_{4}{ }^{+} / \mathrm{NO}_{3}{ }^{-}$ratios and triterpenoid accumulation in Cyclocarya paliurus was influenced by sampling time or the organs being tested [36]. This was also implied in a recent study based on stevia, where different $\mathrm{N}$ form-induced effects on SGs were observed when supplied with different plant growth regulators [37]. Taking all of these observations together, although $\mathrm{N}$ form-regulated terpenoid metabolism can be influenced by species and the organ being tested, there appears to be a positive role of $\mathrm{NO}_{3}{ }^{-}$nutrition in SGs synthesis.

We have previously demonstrated that application of $\mathrm{N}$ as urea boosted biomass but this effectively "diluted" SGs content [15]. However, in this present work, different forms of $\mathrm{N}$ did not result in a significant difference in either leaf $\mathrm{N}$ content or biomass (Table 1), but there was higher SGs content in $\mathrm{NO}_{3}{ }^{-}$-treated plants (Figure 1). Crucially, this could reduce any dilution effect of growth on the levels of SGs. To further elucidate the underlying mechanism for this, transcriptomic analysis was performed. Further, 
we validated the RNA-seq data through qRT-PCR detection, as also used in many other studies [38-41]. Accordingly, the similar expression patterns of specific SG synthesis-related genes from RNA-Seq and qRT-PCR results confirmed the validity of our transcriptome analysis results (Figure 7). These transcriptomic analyses suggested the key genes, TFs and pathways in regulating specific metabolism, most of which have been previously reported in terpenoid-enriched plants including Finger Citron [42], Ferula assafoetida [43], Dendrobium officinale [44], as well as stevia [17,45]. The KEGG results clearly indicated that $\mathrm{NO}_{3}{ }^{-}$mostly upregulates the pathways relating to secondary metabolism, with "diterpenoid biosynthesis" being the most significant for SGs. Other important pathways were "phenylpropanoid biosynthesis" and "wax biosynthesis", both of which were also supported by the MapMan analysis (Figures 3 and 4). Such results imply that $\mathrm{N}$ forms play a definite regulatory role in metabolic reprogramming, which has been documented in poplar [46] and tea [47]. $\mathrm{NH}_{4}{ }^{+}$upregulates the primary amino acid metabolism as well as the secondary alkaloids metabolism, which would correspondingly reduce the metabolic flow to terpenoids $[48,49]$. This aligned with our results that amino acid synthesis-related pathways prominent in $\mathrm{NO}_{3}{ }^{-}$downregulated DEGs (Supplemental Figure S2).

Interestingly, different modules of SG biosynthesis responded differently to $\mathrm{N}$ forms (Figure 5). For instance, the expressions of genes in the P450 and glycosylation modules were not significantly affected by $\mathrm{N}$ form, which suggest that these genes were not driving the increases in $\mathrm{NO}_{3}{ }^{-}$-mediated SGs synthesis, although they play vital roles in either terpenoid skeleton modification or glycosylation [50]. In contrast, the SrDXS and SrDXR families were upregulated by $\mathrm{NO}_{3}{ }^{-}$, suggesting that these genes contributed to increased SGs synthesis, with their function in mediating metabolic flow into the MEP pathway. This aligns with MEP being the main pathway in providing the 5-carbon isoprenoid unit for SG biosynthesis $[29,51]$. Even more striking was the upregulation of genes encoding GGPPS and CPS, by $\mathrm{NO}_{3}{ }^{-}$feeding. This was an important observation as these are the key catalytic enzymes responsible for ent-diterpenoid synthesis and are highly conserved in all terpenoid-synthesizing organisms [52]. Thus, enhanced diterpene synthesis and accumulation have been achieved by overexpressing the CPS or GGPPS gene in Salvia species [52,53] and tobacco [54]. Similarly, Jassbi et al. [55] demonstrated that the silencing of GGPPS disrupted the synthesis of 17-hydroxygeranyllinalool diterpenoid glycosides, together with the increased susceptibility to tobacco hornworm. Overall, the above findings indicated that the $\mathrm{NO}_{3}{ }^{-}$-mediated SG biosynthesis was related to the upregulated terpenoid biosynthetic genes, especially GGPPS and CPS.

Beyond demonstrating some upregulated terpenoid biosynthetic gene expression, we sought to suggest some key $\mathrm{NO}_{3}{ }^{-}$responsive regulatory components. In defining these, TFs were the obvious targets as these are key factors determining plant secondary metabolism in response to environmental changes (including $\mathrm{N}$ forms) and activating the promoters of specific genes [56,57]. In this study, 23 TFs were screened and WRKY and MYB TFs were the most enriched and positively responded to $\mathrm{NO}_{3}{ }^{-}$(Figure 6). Notably, it seemed that all previously documented WRKY TFs play positive functions in endogenous terpenoid biosynthesis (Supplemental Table S2). This aligns with reports that WRKY TFs regulate plant defence via secondary metabolism regulation [58,59]. Moreover, studies in Salvia miltiorrhiza, Panax ginseng and Withania somnifera all show that WRKY TFs can positively direct terpenoid biosynthesis, by binding to the W-box sequences in promoters of specific genes, such as CPS [60], squalene epoxidase [59,61] and DXR [62]. Interestingly, Sun et al. [63] demonstrated that the PqWRKY1 in Panax quinquefolius, that associated with the increased production of ginsenosides, can also upregulate triterpene biosynthetic genes in Arabidopsis, indicating the conserved functions of WRKY across different plant species. In short, the above findings support a positive role of WRKY TFs in the synthesis of terpenoids, including SGs in stevia plants. Considering MYB TFs, they have been reported to play key roles in plant growth, defence, as well as secondary metabolism. Although MYB TFs may regulate terpenoid biosynthesis as either activators or repressors (Supplemental Table S3), it seems that they have a positive regulatory effect in $\mathrm{NO}_{3}{ }^{-}$-mediated SGs 
synthesis, which was also confirmed in our more recent work [17]. Terpenoid-relevant MYB targeted promoters include those encoding GGPPS [64], dammarenediol synthase [65], CPS [66] and other TPS genes $[67,68]$. Other TFs such as AP2/ERF-ERF and bHLH have also been reported to play regulatory roles in terpenoid synthesis $[69,70]$, but we could find no evidence of these being significant factors mediating $\mathrm{N}$ form-mediated metabolic reprogramming. Further, although HSF TFs were upregulated by $\mathrm{NO}_{3}{ }^{-}$rather than $\mathrm{NH}_{4}{ }^{+}$, rather than affecting plant secondary metabolism, they seem to be mainly regulated plant biotic/abiotic stress responses through various signalling pathways such as calcium, reactive oxygen species and abscisic acid [71,72]. Taking all of these observations into account, we suggest that WRKY and MYB TFs were the key factors responding to $\mathrm{N}$ forms and mediating the synthesis of terpenoid compounds, including SGs in our study.

To summarize, we have derived a schematic model to show that $\mathrm{NO}_{3}{ }^{-}$promoted the synthesis of SGs in stevia leaves by regulating the expression of SGs-related genes combining by key TFs, especially MYB and WRKY (Figure 8).

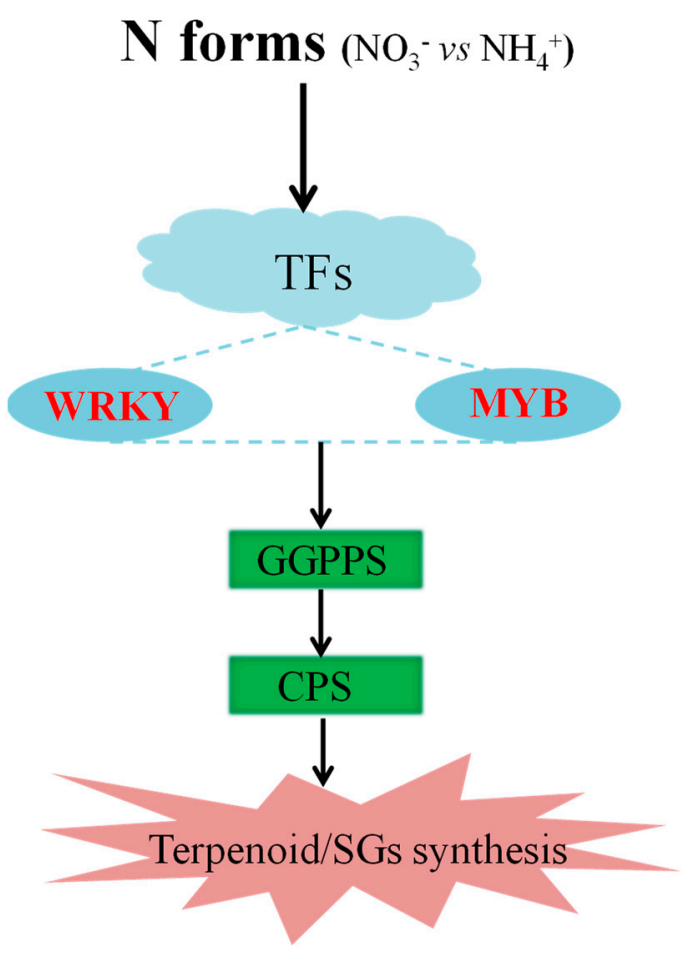

Figure 8. A schematic model showing the regulation of steviol glycosides synthesis by $\mathrm{N}$ formsMYB/WRKY-GGPPS/CPS in stevia leaves. When feeding with nitrate nitrogen (N-N) rather than ammonium nitrogen (A-N), specific transcription factors in stevia leaves, especially those belonging to MYB and WRKY families, are activated. Theses TFs can regulate the expressions of terpene synthesis-related genes such as GGPPS and CPS, thereby promoting the production of steviol glycosides.

\section{Materials and Methods}

\subsection{Plant Material and Experimental Conditions}

Field and pot experiments were simultaneously conducted at the Institute of Botany, Jiangsu Province, and the Chinese Academy of Sciences in 2019, from June to September. In the experiments, the similarly sized seedlings of stevia (Stevia rebaudiana Bertoni) cultivar Zhongshan No. $8^{\prime}$ were used. The basic properties of the experimental soil used here have been previously described [17], and the total $\mathrm{N}$, Olsen-phosphorus and $\mathrm{NH}_{4} \mathrm{OAc}$-potassium contents are $2.41 \mathrm{mg} \mathrm{g}^{-1}, 60.91 \mathrm{mg} \mathrm{kg}^{-1}$ and $283.22 \mathrm{mg} \mathrm{kg}^{-1}$, respectively.

Both field and pot experiments contained two $\mathrm{N}$ fertilization regimes of (1) ammonium $\mathrm{N}\left(\mathrm{NH}_{4}{ }^{+}\right)$fertilization (in the form of ammonium sulfate) and (2) nitrate $\mathrm{N}\left(\mathrm{NO}_{3}{ }^{-}\right)$ 
fertilization (in the form of calcium nitrate). These two treatments only differed in the $\mathrm{N}$ fertilizer forms with $\mathrm{N}$ fertilization rate and topdressing strategies being identical. The fertilization rates of $\mathrm{N}$, phosphorus and potassium for the field experiment were $300 \mathrm{~kg} \mathrm{ha}^{-1}$, $75 \mathrm{~kg} \mathrm{ha}^{-1}$ and $90 \mathrm{~kg} \mathrm{ha}^{-1}$, respectively. $\mathrm{N}$ fertilizers were applied three times, at a ratio of $50 \%, 30 \%, 20 \%$ separately before transplanting, at the fast-growing stage and late-branching stage, as described previously [16]. Phosphate fertilizers were all applied before transplanting in the form of calcium superphosphate, while potassium fertilizers were applied twice in equal amounts, respectively, before transplanting and the fast-growing stage. For the pot experiment, all fertilization rates and strategies were consistent with the field experiment, with the specific fertilizer amounts calculated according to the relationship between the pot soil weight and the field soil weight of the cultivated layer $(15 \mathrm{~cm})$. In the field experiment, the plots with different fertilization regimes were arranged at intervals to reduce the discrete influence of environmental factors, but this was not done in the pot experiment due to the stable greenhouse conditions.

\subsection{Sampling and Processing}

Plants in field and pot experiments were harvested at the flower bud stage that is defined as the harvest stage in stevia cultivation. Six biological replicates were taken for each treatment. Half of these plants in one treatment (three replicates) were harvested as dry samples, while the rest of the plants were collected as fresh samples. Specifically, three of the replications were cut alongside the stem base and then divided into stems and leaves in the lab after washing with distilled water. Then, all these samples were separately dried at $105^{\circ} \mathrm{C}$ for $30 \mathrm{~min}$ and then at $70{ }^{\circ} \mathrm{C}$ to constant weight, prior to being ground and mixed. Simultaneously, the fresh leaves of the remaining replicates were ground in liquid nitrogen, and then stored in $\mathrm{a}-80^{\circ} \mathrm{C}$ freezer for further analysis. The dried samples were used for the measurements of total $\mathrm{N}(\mathrm{TN})$, total carbon (TC), and SG content. The fresh samples were used for the measurements of leaf ammonium and nitrate content, as well as for RNA-seq work.

\subsection{Measurement of $\mathrm{TN}, \mathrm{NO}_{3}{ }^{-}$Content, $\mathrm{NH}_{4}{ }^{+}$Content in Stevia Leaves}

The leaf total $\mathrm{N}$ content was measured following the $\mathrm{H}_{2} \mathrm{SO}_{4}-\mathrm{H}_{2} \mathrm{O}_{2}$ digestion method of Kjeldahl [73]. The extraction and measurement of $\mathrm{NO}_{3}{ }^{-}$followed the method of Cataldo et al. [74], while the measurement of $\mathrm{NH}_{4}{ }^{+}$used the method of Lin and Kao [75].

\subsection{Extraction and Analysis of Leaf Steviol Glycosides (SGs) Content}

The detection of leaf SGs content was conducted according to the method of Sun et al. [15], with a slight modification. Briefly, the leaf samples were ground with $80 \%$ ethanol and then placed in a boiling water bath for $1 \mathrm{~h}$ before centrifugation at $12,000 \times g$ for $10 \mathrm{~min}$. The supernatants would be then rotary-evaporated and redissolved in distilled water for further high-performance liquid chromatography (HPLC) detection. The HPLC working conditions were kept the same as previously reported, and the contents of different SG components were calculated according to standard curves of Reb A, STV, and Reb C (99.99\% pure, ChromaDex, Irvine, CA, USA).

\subsection{Transcriptome Analysis of Stevia Leaves}

The RNA isolation and transcriptome analysis procedures were performed by staff at Beijing BioMarker Technology (Beijing, China), as previously reported [17]. Briefly, total RNA was isolated using RNAiso Plus (Takara Bio Inc., Shiga, Japan). The RNA degradation, purity and integrity were then assessed according to the manufacturer's instructions. Library preparation for RNA-Seq was generated using the NEBNext ${ }^{\circledR}$ Ultra $^{\mathrm{TM}}$ RNA Library Prep Kit for Illumina ${ }^{\circledR}$ (NEB, San Diego, CA, USA), and the library preparations were sequenced using an Illumina HiSeq X-ten platform.

The high-quality clean-read data were obtained by removing reads containing adapter contamination and eliminating the low-quality reads. HISAT 2 program and StringTie 
were used for the reads mapping and assembly [76,77], with the genome data of stevia referenced for further annotation [29]. Functional annotation of all identified genes was performed through NCBI nonredundant protein sequences, nonredundant nucleotide sequences, SwissProt, Gene Ontology (GO), Clusters of Orthologous Groups of proteins (KOG/COG) and the Kyoto Encyclopedia of Genes and Genomes (KEGG).

\subsection{Differentially Expressed Genes (DEGs) and Enrichment Analysis}

Gene expression levels were represented by the FPKM (fragments per kilobase of exon per million fragments mapped reads) value using RNA-seq data. The DESeq2 was used to calculate the differences in the expression between $\mathrm{NH}_{4}{ }^{+}$and $\mathrm{NO}_{3}{ }^{-}$treatments. We used a false discovery rate (FDR) of 0.01 and a fold-change of 2 as the threshold for DEGs identification. The subsequently GO and KEGG enrichment analyses were performed based on all of these DEGs, implemented by the GOseq R package-based Wallenius noncentral hypergeometric distribution and KOBAS (2.0) software (center for bioinformatics of Peking University, Beijing, China) [78].

\subsection{MapMan Analysis}

For metabolic pathway analysis, stevia transcripts were annotated and classified into MapMan BINs using plaBi dataBase (https:/ / www.plabipd.de/portal/mercator-sequenceannotation (accessed on 5 March 2021)), and the functional category analysis of DEGs was performed by MapMan version 3.6.0 (http:/ / mapman.gabipd.org/web/guest (accessed on 5 March 2021), Max Planck Institute for Molecular Plant Physiology, Golm, Potsdam, Germany).

\subsection{Quantitative Real-Time PCR ( $q R T-P C R$ ) Validation of DEGs}

In this study, nine genes involved in SGs synthesis were selected for the verification of the DEG results. As shown in Supplemental Table S4, Actin was used as endogenous control and the primers were designed using Primer 3.0 program. qRT-PCR reactions were conducted on an ABI 7500 real-time PCR system using SYBR Green master mix (TaKaRa, Dalian, China) and the relative expression of target genes was calculated by the $2^{-\Delta \Delta \mathrm{Ct}}$ method [79].

\subsection{Data Availability}

Data sets of this bio-project (PRJNA745392) are available at the NCBI Sequence Read Archive (SRA) with the accession of SUB9990898. SAMN20165632, SAMN20165633 and SAMN20165634 are the bio-sample names of the control group (A-N), while SAMN20165635, SAMN20165636, and SAMN20165637are those for the treatment group (N-N).

\subsection{Statistical Analysis}

One-way analysis of variance (ANOVA) and two-way ANOVA were respectively used to assess differences for each parameter among treatments and the interaction between treatments and experimental cultures, using the SPSS 16.0 (IBM, Armonk, NYC, USA) statistical software package. Means and calculated standard deviations were reported. Significance was tested at the 5\% level.

\section{Conclusions}

Our results showed that $\mathrm{NO}_{3}{ }^{-}$, rather than $\mathrm{NH}_{4}{ }^{+}$, can significantly promote SGs synthesis in stevia leaves, without losing leaf biomass. Through transcriptomic analysis, we found that $\mathrm{N}$ forms can induce metabolic reprogramming including $\mathrm{NO}_{3}{ }^{-}$-enhanced terpenoid synthesis. Such influence may be dependent on the activation of the MYB/WRKY TFs on the expressions of key enzymes of terpene synthesis. These represent potential targets to increase SGs via plant breeding via even transgenic or gene-editing approaches. More immediately, the proper use of $\mathrm{NO}_{3}{ }^{-}$fertilization seems likely to be an immediate and cost-effective manner to boost SG yield from stevia. 
Supplementary Materials: The following are available online at https://www.mdpi.com/article/10 $.3390 /$ ijms22168549/s1.

Author Contributions: Conceptualization, Y.S. and H.Y.; formal analysis, Y.S., T.Z., Y.Y. and H.T.; investigation, Y.S. and X.X.; methodology, Y.S.; project administration, Y.S. and T.Z.; writing-original draft, Y.S.; writing—review and editing, L.A.J.M. All authors have read and agreed to the published version of the manuscript.

Funding: This work was funded by the Natural Science Foundation of Jiangsu Province (BK20180312, BK20201243) and the National Natural Science Foundation of China (31901597). Luis Alejandro Jose Mur.'s contribution is aided by the Biotechnology and Biological Sciences Research Council (BBSRC, $\mathrm{UK}$ ) "A China-UK joint phenomics consortium to dissect the basis of crop stress resistance in the face of climate change" (grant No. BB/R02118X/1), exchange grant.

Institutional Review Board Statement: Not applicable.

Informed Consent Statement: Not applicable.

Data Availability Statement: The data that support the findings of this study are openly available in the NCBI Sequence Read Archive (SRA) under projects PRJNA745392.

Conflicts of Interest: The authors declare no conflict of interest.

\section{References}

1. Edwards, C.H.; Rossi, M.; Corpe, C.P.; Butterworth, P.J.; Ellis, P.R. The role of sugars and sweeteners in food, diet and health: Alternatives for the future. Trends Food Sci. Technol. 2016, 56, 158-166. [CrossRef]

2. Bray, G.A.; Popkin, B.M. Dietary sugar and body weight: Have we reached a crisis in the epidemic of obesity and diabetes?: Health be damned! Pour on the sugar. Diabetes Care 2014, 37, 950-956. [CrossRef]

3. Yadav, S.K.; Guleria, P. Steviol glycosides from Stevia: Biosynthesis pathway review and their application in foods and medicine. Crit. Rev. Food Sci. 2012, 52, 988-998. [CrossRef]

4. Gardana, C.; Scaglianti, M.; Simonetti, P. Evaluation of steviol and its glycosides in Stevia rebaudiana leaves and commercial sweetener by ultra-high-performance liquid chromatography-mass spectrometry. J. Chromatogr. A 2010, 1217, 1463-1470. [CrossRef]

5. Wang, J.; Li, S.; Xiong, Z.; Wang, Y. Pathway mining-based integration of critical enzyme parts for de novo biosynthesis of steviolglycosides sweetener in Escherichia coli. Cell Res. 2016, 26, 258-261. [CrossRef]

6. Kim, M.J.; Zheng, J.; Liao, M.H.; Jang, I.C. Overexpression of SrUGT76G1 in Stevia alters major steviol glycosides composition towards improved quality. Plant Biotechnol. J. 2018, 17, 1037-1047. [CrossRef] [PubMed]

7. Yang, Y.; Huang, S.; Han, Y.; Yuan, H.; Gu, C.; Wang, Z. Environmental cues induce changes of steviol glycosides contents and transcription of corresponding biosynthetic genes in Stevia rebaudiana. Plant Physiol. Biochem. 2015, 86, 174-180. [CrossRef]

8. Mandal, S.; Evelin, H.; Giri, B.; Singh, V.P.; Kapoor, R. Arbuscular mycorrhiza enhances the production of stevioside and rebaudioside-A in Stevia rebaudiana via nutritional and non-nutritional mechanisms. Appl. Soil Ecol. 2013, 72, 187-194. [CrossRef]

9. Kumar, R.; Sood, S.; Sharma, S.; Kasana, R.C.; Pathania, V.L.; Singh, B.; Singh, R.D. Effect of plant spacing and organic mulch on growth, yield and quality of natural sweetener plant Stevia and soil fertility in western Himalayas. Int. J. Plant Prod. 2014, 8 , 311-334.

10. Scheible, W.R.; Morcuende, R.; Czechowski, T.; Fritz, C.; Osuna, D.; Palacios-Rojas, N.; Schindelasch, D.; Thimm, O.; Udvardi, M.K.; Stitt, M. Genome-wide reprogramming of primary and secondary metabolism, protein synthesis, cellular growth processes, and the regulatory infrastructure of Arabidopsis in response to nitrogen. Plant Physiol. 2004, 136, 2483-2499. [CrossRef]

11. Msanne, J.; Xu, D.; Konda, A.R.; Casas-Mollano, J.A.; Awada, T.; Cahoon, E.B.; Cerutti, H. Metabolic and gene expression changes triggered by nitrogen deprivation in the photoautotrophically grown microalgae Chlamydomonas reinhardtii and Coccomyxa sp. C-169. Phytochemistry 2012, 75, 50-59. [CrossRef]

12. Tavarini, S.; Sgherri, C.; Ranieri, A.M.; Angelini, L.G. Effect of nitrogen fertilization and harvest time on steviol glycosides, flavonoid composition, and antioxidant properties in Stevia rebaudiana Bertoni. J. Agric. Food Chem. 2015, 63, 7041-7050. [CrossRef]

13. Rodrigues, M.Â.; Afonso, S.; Ferreira, I.Q.; Arrobas, M. Response of stevia to nitrogen fertilization and harvesting regime in Northeastern Portugal. Arch. Agron. Soil Sci. 2017, 63, 626-637. [CrossRef]

14. Pal, P.K.; Kumar, R.; Guleria, V.; Mahajan, M.; Prasad, R.; Pathania, V.; Gill, B.S.; Singh, D.; Chand, G.; Singh, B.; et al. Crop-ecology and nutritional variability influence growth and secondary metabolites of Stevia rebaudiana Bertoni. BMC Plant Biol. 2015, 15, 67. [CrossRef]

15. Sun, Y.; Hou, M.; Mur, L.A.J.; Yang, Y.; Zhang, T.; Xu, X.; Huang, S.; Tong, H. Nitrogen drives plant growth to the detriment of leaf sugar and steviol glycosides metabolisms in Stevia (Stevia rebaudiana Bertoni). Plant Physiol. Biochem. 2019, 141, $240-249$. [CrossRef]

16. Sun, Y.; Yang, Y.; Hou, M.; Huang, X.; Zhang, T.; Huang, S.; Xu, X.; Yuan, H. Optimized nitrogen topdressing strategies enhance steviol glycoside productivity in stevia (Stevia rebaudiana Bertoni) plants. J. Soil Sci. Plant Nutr. 2020, 20, 1133-1143. [CrossRef] 
17. Sun, Y.; Xu, X.; Zhang, T.; Yang, Y.; Tong, H.; Yuan, H. Comparative transcriptome analysis provides insights into steviol glycoside synthesis in stevia (Stevia rebaudiana Bertoni) leaves under nitrogen deficiency. Plant Cell Rep. 2021. [CrossRef]

18. Miflin, B.J.; Habash, D.Z. The role of glutamine synthetase and glutamate dehydrogenase in nitrogen assimilation and possibilities for improvement in the nitrogen utilization of crops. J. Exp. Bot. 2002, 53, 979-987. [CrossRef]

19. Masclaux-Daubresse, C.; Reisdorf-Cren, M.; Pageau, K.; Lelandais, M.; Grandjean, O.; Kronenberger, J.; Valadier, M.H.; Feraud M.; Jouglet, T.; Suzuki, A. Glutamine synthetase-glutamate synthase pathway and glutamate dehydrogenase play distinct roles in the sink-source nitrogen cycle in tobacco. Plant Physiol. 2006, 140, 444-456. [CrossRef] [PubMed]

20. Bloom, A.J. Photorespiration and nitrate assimilation: A major intersection between plant carbon and nitrogen. Photosynth. Res. 2015, 123, 117-128. [CrossRef]

21. Sun, Y.; Li, Y.; Wang, B.; Li, Y.; Ding, L.; Wang, M.; Luis, A.J.M.; Fan, X.; Shen, Q.; Guo, S. Leaf nitrate accumulation influences the photorespiration of rice (Oryza sativa L.) seedlings. Plant Soil 2020, 456, 323-338. [CrossRef]

22. Masumoto, C.; Miyazawa, S.; Ohkawa, H.; Fukuda, T.; Taniguchi, Y.; Murayama, S.; Kusano, M.; Saito, K.; Fukayama, H.; Miyao, M. Phosphoenolpyruvate carboxylase intrinsically located in the chloroplast of rice plays a crucial role in ammonium assimilation. Proc. Natl. Acad. Sci. USA 2010, 107, 5226-5231. [CrossRef] [PubMed]

23. Setien, I.; Vega-Mas, I.; Celestino, N.; Calleja-Cervantes, M.E.; Gonzalez-Murua, C.; Estavillo, J.M.; Gonzalez-Moro, M.B. Root phosphoenolpyruvate carboxylase and NAD-malic enzymes activity increase the ammonium-assimilating capacity in tomato. $J$. Plant Physiol. 2014, 171, 49-63. [CrossRef]

24. Fallovo, C.; Schreiner, M.; Schwarz, D.; Colla, G.; Krumbein, A. Phytochemical changes induced by different nitrogen supply forms and radiation levels in two leafy Brassica species. J. Agric. Food Chem. 2011, 59, 4198-4207. [CrossRef] [PubMed]

25. Zhu, Z.; Yu, M.; Chen, Y.; Guo, Q.; Zhang, L.; Shi, H.; Liu, L. Effects of ammonium to nitrate ratio on growth, nitrogen metabolism, photosynthetic efficiency and bioactive phytochemical production of Prunella vulgaris. Pharm. Biol. 2014, 52, 1518-1525. [CrossRef] [PubMed]

26. Zhong, C.; Jian, S.F.; Chen, D.L.; Huang, X.J.; Miao, J.H. Organic nitrogen sources promote andrographolide biosynthesis by reducing nitrogen metabolism and increasing carbon accumulation in Andrographis paniculata. Plant Physiol. Biochem. 2021, 164, 82-91. [CrossRef]

27. Zhang, J.; Lv, J.; Xie, J.; Gan, Y.; Coulter, J.A.; Yu, J.; Li, J.; Wang, J.; Zhang, X. Nitrogen source affects the composition of metabolites in pepper (Capsicum annuum L.) and regulates the synthesis of Capsaicinoids through the GOGAT-GS pathway. Foods 2020, 9 , 150. [CrossRef]

28. Aghaye Noroozlo, Y.; Souri, M.K.; Delshad, M. Effects of soil application of amino acids, ammonium, and nitrate on nutrient accumulation and growth characteristics of Sweet Basil. Commun. Soil Sci. Plant Anal. 2019, 50, 2864-2872. [CrossRef]

29. Xu, X.; Yuan, H.; Yu, X.; Huang, S.; Sun, Y.; Zhang, T.; Liu, Q.; Tong, H.; Zhang, Y.; Wang, Y.; et al. The chromosome-level Stevia genome provides insights into steviol glycoside biosynthesis. Hortic. Res. 2021, 8, 129. [CrossRef] [PubMed]

30. Guo, S.; Zhou, Y.; Gao, Y.; Li, Y.; Shen, Q. New insights into the nitrogen form effect on photosynthesis and photorespiration. Pedosphere 2007, 17, 601-610. [CrossRef]

31. Guo, S.; Zhou, Y.; Shen, Q.; Zhang, F. Effect of ammonium and nitrate nutrition on some physiological processes in higher plants-growth, photosynthesis, photorespiration, and water relations. Plant Biol. 2007, 9, 21-29. [CrossRef]

32. Chen, Y.; Fei, Y.; Cai, M.; Luo, J. Effects of amino acids, nitrate, and ammonium on the growth and taxol production in cell cultures of Taxus yunnanensis. Plant Growth Regul. 2003, 41, 265-268. [CrossRef]

33. Zhang, J.; Gao, W.; Wang, J.; Li, X.; Xiao, P. Improvement of growth and periplocin yield of Periploca sepium adventitious root cultures by altering nitrogen source supply. Chin. Herb. Med. 2011, 3, 226-231.

34. Zhong, J.; Wang, S. Effects of nitrogen source on the production of ginseng saponin and polysaccharide by cell cultures of Panax quinquefolium. Process Biochem. 1998, 33, 671-675. [CrossRef]

35. Shekofteh, H.; Salari, N. Influence of hydrogel polymer and $\mathrm{NO}_{3}{ }^{-}: \mathrm{NH}_{4}{ }^{+}$ratios on dill (Anethum graveolens L.) seed essential oil composition and yield. Desert 2016, 21, 91-101.

36. Qin, J.; Yue, X.; Shang, X.; Fang, S. Nitrogen forms alter triterpenoid accumulation and related gene expression in Cyclocarya paliurus (Batalin) Iljinsk. seedlings. Forests 2020, 11, 631. [CrossRef]

37. Hasanaklou, H.T.; Ghadim, A.E.K.; Moradi, F.; Ghodehkahriz, S.J.; Gholipouri, A. The effects of $\mathrm{NH}_{4}{ }^{+}$and $\mathrm{NO}_{3}{ }^{-}$and plant growth regulators on the accumulation of nutrients, carbohydrates and secondary metabolites of Stevia rebaudiana Bertoni. Sugar Tech 2020, 23, 65-76. [CrossRef]

38. Liu, H.; Gu, J.; Lu, Q.; Li, H.; Hong, Y.; Chen, X.; Ren, L.; Deng, L.; Liang, X. Transcriptomic analysis reveals the high-oleic acid feedback regulating the homologous gene expression of Stearoyl-ACP Desaturase 2 (SAD2) in peanuts. Int. J. Mol. Sci. 2019, 20, 3091. [CrossRef]

39. Guan, L.; Haider, M.S.; Khan, N.; Nasim, M.; Jiu, S.; Fiaz, M.; Zhu, X.; Zhang, K.; Fang, J. Transcriptome sequence analysis elaborates a complex defensive mechanism of grapevine (Vitis vinifera L.) in response to salt stress. Int. J. Mol. Sci. 2018, 19, 4019. [CrossRef] [PubMed]

40. Deng, N.; Hou, C.; He, B.; Ma, F.; Song, Q.; Shi, S.; Liu, C.; Tian, Y. A full-length transcriptome and gene expression analysis reveal genes and molecular elements expressed during seed development in Gnetum luofuense. BMC Plant Biol. 2020, 20, 531. [CrossRef] 
41. Miao, L.; Di, Q.; Sun, T.; Li, Y.; Duan, Y.; Wang, J.; Yan, Y.; He, C.; Wang, C.; Yu, X. Integrated metabolome and transcriptome analysis provide insights into the effects of grafting on fruit flavor of cucumber with different rootstocks. Int. J. Mol. Sci. 2019, 20, 3592. [CrossRef] [PubMed]

42. Xu, Y.; Zhu, C.; Xu, C.; Sun, J.; Grierson, D.; Zhang, B.; Chen, K. Integration of metabolite profiling and transcriptome analysis reveals genes related to volatile terpenoid metabolism in Finger Citron (C. medica var. sarcodactylis). Molecules 2019, $24,2564$. [CrossRef]

43. Amini, H.; Naghavi, M.R.; Shen, T.; Wang, Y.; Nasiri, J.; Khan, I.A.; Fiehn, O.; Zerbe, P.; Maloof, J.N. Tissue-specific transcriptome analysis reveals candidate genes for terpenoid and phenylpropanoid metabolism in the medicinal plant Ferula assafoetida. Genes Genom. Genet. 2019, 9, 807-816. [CrossRef]

44. Li, N.; Dong, Y.; Lv, M.; Qian, L.; Sun, X.; Liu, L.; Cai, Y.; Fan, H. Combined analysis of volatile terpenoid metabolism and transcriptome reveals transcription factors related to terpene synthase in two cultivars of Dendrobium officinale Flowers. Front. Genet. 2021, 12, 661296. [CrossRef]

45. Singh, G.; Pal, P.; Masand, M.; Seth, R.; Kumar, A.; Singh, S.; Sharma, R.K. Comparative transcriptome analysis revealed gamma-irradiation mediated disruption of floral integrator gene(s) leading to prolonged vegetative phase in Stevia rebaudiana Bertoni. Plant Physiol. Biochem. 2020, 148, 90-102. [CrossRef]

46. Poovaiah, C.R.; Phalen, C.; Sniffen, G.T.; Coleman, H.D. Growth and transcriptional changes in poplar under different nitrogen sources. Plant Mol. Biol. Rep. 2019, 37, 291-302. [CrossRef]

47. Yang, Y.; Wang, F.; Wan, Q.; Ruan, J. Transcriptome analysis using RNA-Seq revealed the effects of nitrogen form on major secondary metabolite biosynthesis in tea (Camellia sinensis) plants. Acta Physiol. Plant. 2018, 40, 1-17. [CrossRef]

48. Guo, X.; Zu, Y.; Tang, Z. Physiological responses of Catharanthus roseus to different nitrogen forms. Acta Physiol. Plant. 2011, 34, 589-598. [CrossRef]

49. Wang, M.; Gu, Z.; Wang, R.; Guo, J.; Ling, N.; Firbank, L.G.; Guo, S. Plant primary metabolism regulated by nitrogen contributes to plant-pathogen interactions. Plant Cell Physiol. 2019, 60, 329-342. [CrossRef] [PubMed]

50. Zheng, X.; Li, P.; Lu, X. Research advances in cytochrome P450-catalysed pharmaceutical terpenoid biosynthesis in plants. J. Exp. Bot. 2019, 70, 4619-4630. [CrossRef]

51. Volke, D.C.; Rohwer, J.; Fischer, R.; Jennewein, S. Investigation of the methylerythritol 4-phosphate pathway for microbial terpenoid production through metabolic control analysis. Microb. Cell Fact. 2019, 18, 192. [CrossRef]

52. Vaccaro, M.C.; Alfieri, M.; De Tommasi, N.; Moses, T.; Goossens, A.; Leone, A. Boosting the synthesis of pharmaceutically active abietane diterpenes in S. sclarea hairy roots by engineering the GGPPS and CPPS Genes. Front. Plant Sci. 2020, 11, 924. [CrossRef]

53. Shi, M.; Luo, X.; Ju, G.; Li, L.; Huang, S.; Zhang, T.; Wang, H.; Kai, G. Enhanced diterpene tanshinone accumulation and bioactivity of transgenic Salvia miltiorrhiza hairy roots by pathway engineering. J. Agric. Food Chem. 2016, 64, 2523-2530. [CrossRef] [PubMed]

54. Yin, J.L.; Wong, W.S.; Jang, I.C.; Chua, N.H. Co-expression of peppermint geranyl diphosphate synthase small subunit enhances monoterpene production in transgenic tobacco plants. New Phytol. 2017, 213, 1133-1144. [CrossRef]

55. Jassbi, A.R.; Gase, K.; Hettenhausen, C.; Schmidt, A.; Baldwin, I.T. Silencing geranylgeranyl diphosphate synthase in Nicotiana attenuata dramatically impairs resistance to tobacco hornworm. Plant Physiol. 2008, 146, 974-986. [CrossRef] [PubMed]

56. Obertello, M.; Shrivastava, S.; Katari, M.S.; Coruzzi, G.M. Cross-species network analysis uncovers conserved nitrogen-regulated network modules in rice. Plant Physiol. 2015, 168, 1830-1843. [CrossRef]

57. Broun, P.; Liu, Y.; Queen, E.; Schwarz, Y.; Abenes, M.L.; Leibman, M. Importance of transcription factors in the regulation of plant secondary metabolism and their relevance to the control of terpenoid accumulation. Phytochem. Rev. 2006, 5, 27-38. [CrossRef]

58. Meraj, T.A.; Fu, J.; Raza, M.A.; Zhu, C.; Shen, Q.; Xu, D.; Wang, Q. Transcriptional factors regulate plant stress responses through mediating secondary metabolism. Genes 2020, 11, 346. [CrossRef]

59. Singh, A.K.; Kumar, S.R.; Dwivedi, V.; Rai, A.; Pal, S.; Shasany, A.K.; Nagegowda, D.A. A WRKY transcription factor from Withania somnifera regulates triterpenoid withanolide accumulation and biotic stress tolerance through modulation of phytosterol and defense pathways. New Phytol. 2017, 215, 1115-1131. [CrossRef] [PubMed]

60. Deng, C.; Hao, X.; Shi, M.; Fu, R.; Wang, Y.; Zhang, Y.; Zhou, W.; Feng, Y.; Makunga, N.P.; Kai, G. Tanshinone production could be increased by the expression of SmWRKY2 in Salvia miltiorrhiza hairy roots. Plant Sci. 2019, 284, 1-8. [CrossRef]

61. Yao, L.; Wang, J.; Sun, J.; He, J.; Paek, K.; Park, S.; Huang, L.; Gao, W. A WRKY transcription factor, PgWRKY4X, positively regulates ginsenoside biosynthesis by activating squalene epoxidase transcription in Panax ginseng. Ind. Crops Prod. 2020, 154, 112671. [CrossRef]

62. Cao, W.; Wang, Y.; Shi, M.; Hao, X.; Zhao, W.; Wang, Y.; Ren, J.; Kai, G. Transcription factor SmWRKY1 positively promotes the biosynthesis of tanshinones in Salvia miltiorrhiza. Front. Plant Sci. 2018, 9, 554. [CrossRef]

63. Sun, Y.; Niu, Y.; Xu, J.; Li, Y.; Luo, H.; Zhu, Y.; Liu, M.; Wu, Q.; Song, J.; Sun, C.; et al. Discovery of WRKY transcription factors through transcriptome analysis and characterization of a novel methyl jasmonate-inducible PqWRKY1 gene from Panax quinquefolius. Plant Cell Tissue Organ Cult. 2013, 114, 269-277. [CrossRef]

64. Hao, X.; Pu, Z.; Cao, G.; You, D.; Zhou, Y.; Deng, C.; Shi, M.; Nile, S.H.; Wang, Y.; Zhou, W.; et al. Tanshinone and salvianolic acid biosynthesis are regulated by SmMYB98 in Salvia miltiorrhiza hairy roots. J. Adv. Res. 2020, 23, 1-12. [CrossRef]

65. Liu, T.; Luo, T.; Guo, X.; Zou, X.; Zhou, D.; Afrin, S.; Li, G.; Zhang, Y.; Zhang, R.; Luo, Z. PgMYB2, a MeJA-responsive transcription factor, positively regulates the dammarenediol synthase gene expression in Panax Ginseng. Int. J. Mol. Sci. 2019, 20, 2219. [CrossRef] 
66. Reddy, V.A.; Wang, Q.; Dhar, N.; Kumar, N.; Venkatesh, P.N.; Rajan, C.; Panicker, D.; Sridhar, V.; Mao, H.Z.; Sarojam, R. Spearmint R2R3-MYB transcription factor MsMYB negatively regulates monoterpene production and suppresses the expression of geranyl diphosphate synthase large subunit (MsGPPS.LSU). Plant Biotechnol. J. 2017, 15, 1105-1119. [CrossRef] [PubMed]

67. Yang, Z.; Li, Y.; Gao, F.; Jin, W.; Li, S.; Kimani, S.; Yang, S.; Bao, T.; Gao, X.; Wang, L. MYB21 interacts with MYC2 to control the expression of terpene synthase genes in flowers of Freesia hybrida and Arabidopsis thaliana. J. Exp. Bot. 2020, 71, 4140-4158. [CrossRef]

68. Gong, Z.; Luo, Y.; Zhang, W.; Jian, W.; Zhang, L.; Gao, X.; Hu, X.; Yuan, Y.; Wu, M.; Xu, X.; et al. A SlMYB75-centred transcriptional cascade regulates trichome formation and sesquiterpene accumulation in tomato. J. Exp. Bot. 2021, 72, 3806-3820. [CrossRef] [PubMed]

69. Yang, C.Q.; Fang, X.; Wu, X.M.; Mao, Y.B.; Wang, L.J.; Chen, X.Y. Transcriptional regulation of plant secondary metabolism. J. Integr. Plant Biol. 2012, 54, 703-712. [CrossRef] [PubMed]

70. Lu, S. Biosynthesis and regulatory mechanisms of bioactive compounds in Salvia miltiorrhiza, a model system for medicinal plant biology. Crit. Rev. Plant Sci. 2021, 40, 243-283. [CrossRef]

71. Jacob, P.; Hirt, H.; Bendahmane, A. The heat-shock protein/chaperone network and multiple stress resistance. Plant Biotechnol. J. 2017, 15, 405-414. [CrossRef]

72. Guo, M.; Liu, J.H.; Ma, X.; Luo, D.X.; Gong, Z.H.; Lu, M.H. The plant heat stress transcription factors (HSFs): Structure, regulation, and function in response to abiotic stresses. Front. Plant Sci. 2016, 7, 114. [CrossRef] [PubMed]

73. Nelson, D.; Sommers, L. A simple digestion procedure for estimation of ammonium in Kjeldahl soils. J. Environ. Qual. 1972, 1, 423-425. [CrossRef]

74. Cataldo, D.A.; Maroon, M.; Schrader, L.E.; Youngs, V.L. Rapid colorimetric determination of nitrate in plant tissue by nitration of salicylic acid. Commun. Soil Sci. Plant Anal. 1975, 6, 71-80. [CrossRef]

75. Lin, C.C.; Kao, C.H. Disturbed ammonium assimilation is associated with growth inhibition of roots in rice seedlings caused by NaCl. Plant Growth Regul. 1996, 18, 233-238. [CrossRef]

76. Pertea, M.; Pertea, G.M.; Antonescu, C.M.; Chang, T.C.; Mendell, J.T.; Salzberg, S.L. StringTie enables improved reconstruction of a transcriptome from RNA-seq reads. Nat. Biotechnol. 2015, 33, 290-295. [CrossRef]

77. Kim, D.; Langmead, B.; Salzberg, S.L. HISAT: A fast spliced aligner with low memory requirements. Nat. Methods 2015, 12, 357-360. [CrossRef]

78. Yu, R.; Li, D.; Du, X.; Xia, S.; Liu, C.; Shi, G. Comparative transcriptome analysis reveals key cadmium transport-related genes in roots of two pak choi (Brassica rapa L. ssp. chinensis) cultivars. BMC Genom. 2017, 18, 587. [CrossRef] [PubMed]

79. Livak, K.J.; Schmittgen, T.D. Analysis of relative gene expression data using real-time quantitative PCR and the 2(-Delta Delta C(T)) Method. Methods 2001, 25, 402-408. [CrossRef] [PubMed] 